International Journal of Computer Networks \& Communications (IJCNC) Vol.2, No.6, November 2010

\title{
BER PERformanCE EVAluation OF TWO TYPES OF ANTENNA ARRAY-BASED RECEIVERS IN A MULTipath CHANNEL
}

\author{
Rim Haddad ${ }^{1}$, Ridha Bouallègue ${ }^{2}$ \\ Laboratory Research in Telecommunication 6'Tel in High School of Communication of \\ Tunis, Route de Raoued Km 3.5, 2083 Ariana, Tunisia \\ 1 rim.haddadeisima.rnu.tn \\ ${ }^{2}$ ridha.boualleguedsupcom.rnu.tn
}

\begin{abstract}
Smart antennasystems have received much attention in the last few years because they can increase system capacity by dynamically tuning out interference while focusing on the intended user.

In this paper, we focused our research on the performance of two kinds of smart antenna receivers. An analytical model is proposed for evaluating the BER performance using a closed-form expression. Also, for the adaptive array, a simple way to account the multi-access interference can be exploited to evaluate the average probability of error when the users are randomly distributed within an angular sector.

The proposed model confirms the benefits of adaptive antennas in reducing the overall interference level (intercell/intracell) and to find an accurate approximation of the error probability.

In the two kinds of receivers, we assessed the impact of smart antenna systems and we considered the case of conventional single antenna receiver model as reference (single user/single antenna).
\end{abstract}

\section{KEYWORDS}

Beamforming, Direction of Arrival (DoA), BER, Rayleigh fading, Ricean fading

\section{INTRODUCTION}

WIRELESS communication has enjoyed explosive growth over the past decade. A substantial increase in the development of broadband wireless access technologies for evolving wireless Internet services and improved cellular systems has been observed.

A major limitation in capacity is co-channel interference caused by the increasing number of users. The other impairment contributing to the reduction of system performance and capacity is Multiple Access Interference (MAI). Hence, current research activities are focused on reducing these impairments.

On approach that has shown real promise for substantial capacity enhancement is the use of spatial processing with adaptive antenna arrays. Antenna arrays can be thought of as spatial filters in the sense that they can be used to form a beam toward the desired user while spatially rejecting the interferers outside the beam.

In a typical mobile environment, signals from users arrive at different angles to the base station and hence antenna arrays can be used to an advantage. Each multipath of a user may arrive at a different angle, and this angle spread can be exploited using an antenna array[1,2].

The deployment of smart antennas for wireless communication has emerged as one of the leading technologies for achieving high efficiency networks that maximize capacity and improve quality and coverage [1]. 
The Bit Error Ratio (BER) is considered to be one of the most important performance measures for communication systems and hence it has been extensively studied.

In our paper, we propose a novel approach to evaluate the average probability of error by considering an approximation of the spatial filter. Hence, we will derive an analytical model for evaluating the mean BER of two smart antenna receivers.

The analysis is performed assuming Rayleigh and Ricean fading multipath environments. We assume to employ two types of smart antenna receivers: The BPSK smart antenna receiver and the OQPSK smart antenna receiver. An analytical model provides rapid and accurate assessment of the smart antenna system performance under a variety of active users and channel scenarios.

We organize the rest of the paper as follows. In section 2 we introducethe system model, followed by thesmart antenna receiver models in section 3 . The average probability analysis and computation results are provided in section 4 and section 5 respectively. We conclude in section 6.

\section{SYSTEM MODEL}

\subsection{Signal Model with BPSK modulation:}

As a preliminary step, let us introduce the scenario wherein the adaptive antenna operates. We consider a DS-CDMA wireless network with $\mathrm{K}$ subscribers. The base station is equivalent with a uniform linear array (ULA) of M equi-spaced identical elements (Figure1).

The array receives the signals from the $\mathrm{K}$ subscribers located in the far field zone of the array. We assume that all the signals are uncorrelated and each user transmits a binary phase-shift keying (BPSK) symbols.

The base band equivalent model is considered for asynchronous modulation waveforms $\mathrm{S}_{1}(\mathrm{t}), \mathrm{S}_{2}(\mathrm{t}), \ldots \mathrm{S}_{\mathrm{K}}(\mathrm{t})$. The transmitted signal of the $\mathrm{K}^{\mathrm{th}}$ user is:

$$
x_{k}(t)=\sum_{i} b_{k}^{i} S_{k}(t-i T)
$$

$\mathrm{b}_{\mathrm{k}}^{\mathrm{i}} \in\{-1,+1\}$ is the $\mathrm{i}^{\mathrm{th}}$ transmitted BPSK symbol and Tis the symbol interval.The user's signal $\mathrm{x}_{\mathrm{k}}(\mathrm{t})$ propagates through a multipath channel, $\theta_{\mathrm{k}}$ is the DoA of the $\mathrm{k}^{\mathrm{th}}$ user.The impulse response can be written as:

$$
h_{k}(t)=\sum_{m=1}^{L} \alpha_{k, m} \delta\left(t-\tau_{k, m}\right)
$$

Wherein $\alpha_{k, m}$ and $\tau_{k, m}$ are the complex gain and delay of the $m^{\text {th }}$ path. We assume thatall the users have the same number of pathsL, the delay $\tau_{\mathrm{k}, \mathrm{m}} \in[0, \mathrm{~T}[$ have increasing values: $0 \leq$ $\tau_{\mathrm{k}, 1} \leq \tau_{\mathrm{k}, 2} \leq \cdots \leq \tau_{\mathrm{k}, \mathrm{L}}<T$, for $\forall \mathrm{k}$.

In Figure 1 the spatial response of the array due to an incident plane wave from $\theta_{\mathrm{k}}$ direction is modeled by the array steering vector $\mathrm{a}\left(\theta_{\mathrm{k}}\right)$ [3], [4].Wherein $\mathrm{a}\left(\theta_{\mathrm{k}}\right)$ is the $\mathrm{M} \times 1$ vector that describes the array response to the DoA $\theta_{\mathrm{k}}$, and the $\mathrm{n}^{\text {th }}$ element for a linear of half-wavelength spaced antennas is:

$$
\left[\mathrm{a}\left(\theta_{\mathrm{k}}\right)\right]_{\mathrm{n}}=\exp \left(-\mathrm{j}(\mathrm{n}-1) \pi \sin \theta_{\mathrm{k}}\right)
$$




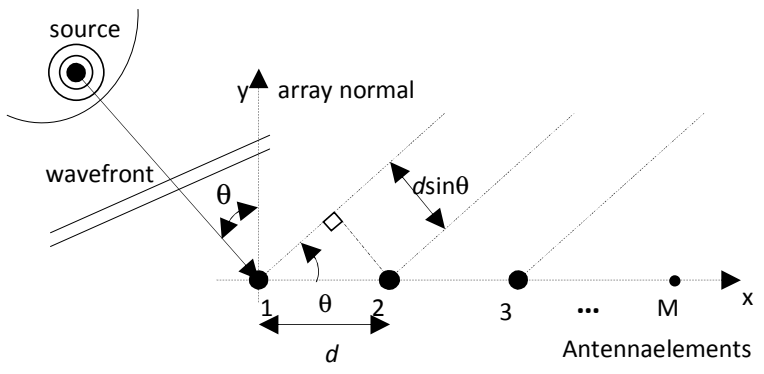

Figure 1.Uniform linear array geometry.

\subsection{System Model with OQPSK modulation:}

The choice of the second model is based on the reverse link (mobile to base station) of the 3G CDMA 2000 Systems. We consider K the total number of active Mobile Stations (MS) in the system, which are randomly distributed in the azimuthal direction, along the arc boundary of the sector cell in the far field of the array. For simplicity, the conventional encoder and interleaver are ignored (this approach is widely used [5] for wireless communication systems employing multiple antennas).

In fact, the signals, transmitted by the $\mathrm{K}$ users, pass through a multipath channel and are received by the BS array antenna. The location of each MS is identified by its Angle of Arrival (AoA) $\theta_{\mathrm{k}}$, which is conventionally measured from the array broadside. The BS receiver is equipped with a conventional Maximum Signal to Noise Ratio beamformer followed by an $\mathrm{L}$ finger non-coherent RAKE combiner [6].

Figure 2 presents the block diagram of the reverse link MS transmitter used in 3G CDMA 2000 systems. We assume that the MS transmitter of each user employs Offset Quadrature Phase Shift Keying (OQPSK) M-ary orthogonal modulation. The OQPSK modulation can be viewed as two independent BPSK signals.

The resultant signal goes into the in-phase (I) and quadrature (Q) channels simultaneously.

The transmitted signal $\mathrm{s}_{\mathrm{k}}$ of the $\mathrm{k}^{\text {th }}$ user can be written as [7]:

$$
s_{k}(t)=W_{k}^{(q)}(t) a_{k}^{(I)}(t) \cos \left(\omega_{c} t\right)+W_{k}^{(q)}\left(t-T_{0}\right) a_{k}^{(Q)}\left(t-T_{0}\right) \sin \left(\omega_{c} t\right)
$$

Where $\mathrm{q}=1,2, \ldots, \mathrm{Q}, \mathrm{W}_{\mathrm{k}}^{(\mathrm{q})}(\mathrm{t})$ is a Hadamard-Walsh function of dimension $\mathrm{Q}$ which represents the $\mathrm{q}^{\text {th }}$ orthogonal signal of the $\mathrm{k}^{\text {th }}$ user's long code sequence, $\mathrm{a}_{\mathrm{k}}(\mathrm{t})$ is the $\mathrm{k}^{\text {th }}$ user's long code sequence, $a_{k}^{(I)}(t)$ and $a_{k}^{(Q)}(t)$ are the in-phase and quadrature phase pseudo-noise (PN) sequences, $T_{0}=T / 2$ is the delay for OQPSK signals.

The power of each user is assumed unity (perfect power control). To simplify our study the PN codes are presented as follows:

$$
a_{k}^{(I)}(t)=\sum_{r} a_{k, r}^{(I)}(t) p\left(t-T_{C}\right)
$$


International Journal of Computer Networks \& Communications (IJCNC) Vol.2, No.6, November 2010

$$
\mathrm{a}_{\mathrm{k}}^{(\mathrm{Q})}(\mathrm{t})=\sum_{\mathrm{r}} \mathrm{a}_{\mathrm{k}, \mathrm{r}}^{(\mathrm{Q})}(\mathrm{t}) \mathrm{p}\left(\mathrm{t}-\mathrm{T}_{\mathrm{C}}\right)
$$

Where $a_{k, r}^{(I)}$ and $a_{k, r}^{(Q)}$ are i.i.d variables taking the values \pm 1 with equal probability and $p(t)$ is the chip pulse shape which is assumed to be rectangular.

The equation (4) can be written as follows:

$$
\begin{gathered}
\mathrm{s}_{\mathrm{k}}(\mathrm{t})=\mathcal{R}\left\{\left[\mathrm{W}_{\mathrm{k}}^{(\mathrm{q})}(\mathrm{t}) \mathrm{a}_{\mathrm{k}}^{(\mathrm{I})}(\mathrm{t})+\mathrm{j} \mathrm{W}_{\mathrm{k}}^{(\mathrm{q})}\left(\mathrm{t}-\mathrm{T}_{0}\right) \mathrm{a}_{\mathrm{k}}^{(\mathrm{Q})}\left(\mathrm{t}-\mathrm{T}_{0}\right)\right] \mathrm{e}^{-\mathrm{j} \omega_{\mathrm{c}} \mathrm{t}}\right\} \\
\mathrm{s}_{\mathrm{k}}(\mathrm{t})=\mathcal{R}\left\{\widetilde{\mathrm{s}_{\mathrm{k}}}(\mathrm{t}) \mathrm{e}^{-\mathrm{j} \omega_{\mathrm{c}} \mathrm{t}}\right\}
\end{gathered}
$$

Where $\widetilde{s_{k}}(t)=S_{k}^{(I)}(t)+j S_{k}^{(Q)}(t)$ is the complex low pass equivalent of the transmitted signal.

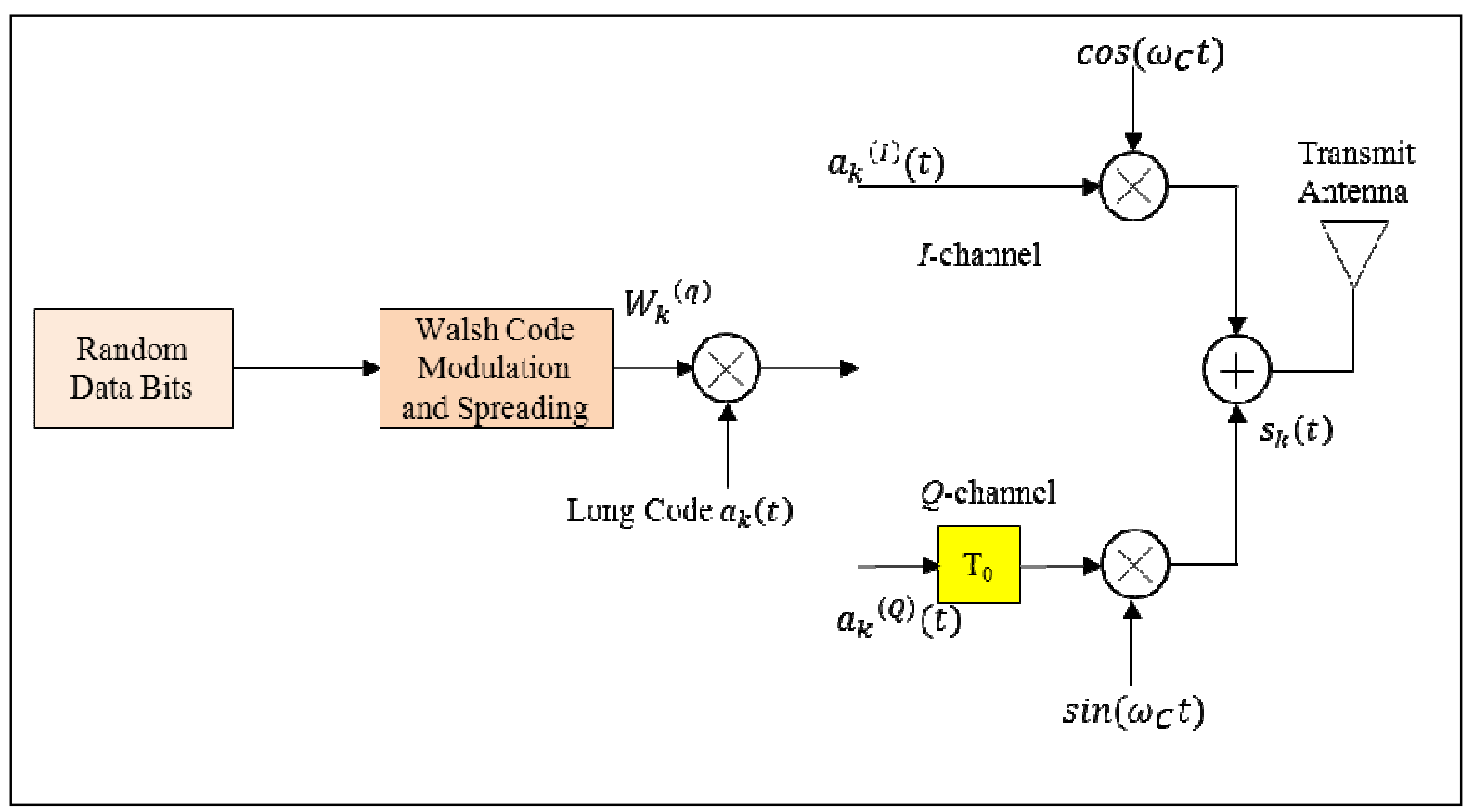

Figure1: Block diagram of mobile station transmitter

The $\mathrm{k}^{\text {th }}$ user propagates through a multipath channel with (AoA) $\theta_{\mathrm{k}}$. We use the channel model presented in chapter 3. The complex equivalent representation of the channel impulse response between the $\mathrm{l}^{\text {th }}$ multipath of the $\mathrm{k}^{\text {th }}$ user and the $\mathrm{n}^{\text {th }}$ element of array antenna is presented as follows:

$$
\begin{gathered}
\tilde{\mathrm{h}}_{\mathrm{k}, \mathrm{l}, \mathrm{n}}(\mathrm{t})=\beta_{\mathrm{k}, \mathrm{l}} \mathrm{e}^{-\mathrm{j}\left(\Phi_{\mathrm{k}, \mathrm{l}}+2 \pi \frac{\mathrm{d}}{\lambda}(\mathrm{n}-1) \sin \theta_{\mathrm{k}}\right)} \delta\left(\mathrm{t}-\bar{\tau}_{\mathrm{k}, \mathrm{l}}\right) \\
\tilde{\mathrm{h}}_{\mathrm{k}, \mathrm{l}, \mathrm{n}}(\mathrm{t})=\beta_{\mathrm{k}, \mathrm{l}} \mathrm{e}^{-\mathrm{j} \varphi_{\mathrm{k}, \mathrm{l}, \mathrm{n}}} \delta\left(\mathrm{t}-\bar{\tau}_{\mathrm{k}, \mathrm{l}}\right)
\end{gathered}
$$

where $\beta_{\mathrm{k}, \mathrm{l}}, \Phi_{\mathrm{k}, \mathrm{l}}$ and $\bar{\tau}_{\mathrm{k}, \mathrm{l}}$ are the path gain, phase and delay respectively, $\varphi_{\mathrm{k}, \mathrm{l}, \mathrm{n}}$ is the overall phase which includes the path phase and the difference in propagation delays between the antennas. In this case of transmitter we assume that path gains follow the Rayleigh and Ricean distributions respectively. 
To simplify our work, we assume that multipath channel parameters $\beta_{k, l}(t)$ and $\varphi_{k, l, n}(t)$ remain constant in the duration of Walsh symbol [8], so $\beta_{k, l}(t)=\beta_{k, l}$ and $\varphi_{\mathrm{k}, \mathrm{l}, \mathrm{n}}(\mathrm{t})=\varphi_{\mathrm{k}, \mathrm{l}, \mathrm{n}}$ for $\mathrm{t} \in\left[0, \mathrm{~T}_{\mathrm{W}}\right]$, where $\mathrm{T}_{\mathrm{W}}$ is the Walsh symbol period.

\section{Smart Antenna Receiver Model:}

\subsection{The BPSK Receiver Model:}

After the Beamforming with the $M \times 1$ spatial filter $w_{p}$ for the $p^{\text {th }} u s e r$, the output of the $p^{\text {th }}$ filter matched to $\mathrm{u}_{\mathrm{p}}(\mathrm{t})$ for the $\mathrm{n}^{\text {th }}$ element of antenna is:

$$
\begin{gathered}
y_{n / p}[j]=\int u_{p}^{*}\left(t-\tau_{p, n}-j T\right) r(t) d t \\
y_{n / p}[j]=\sum_{k=1}^{K} \sum_{i} b_{k}^{i} G\left(\theta_{k / p}\right) \sum_{l=1}^{L} \beta_{k, l} \rho_{k, p}\left((i-j) T+\tau_{p, n}-\tau_{k, l}\right)+\sigma \eta_{n / p}^{\prime}[j]
\end{gathered}
$$

$\mathrm{G}\left(\theta_{\mathrm{k} / \mathrm{p}}\right)=\mathrm{w}_{\mathrm{p}}^{\mathrm{H}} \cdot \mathrm{a}\left(\theta_{\mathrm{k}}\right)$, where $\mathrm{w}_{\mathrm{p}}^{\mathrm{H}}$ is the weight vector and $\mathrm{H}$ denotes Hermitian transpose: is the spatial gain of the beamformer designed for the angle $\theta_{p}$. And $\rho_{k, p}(\tau)=\int u_{k}(t+\tau) u_{p}^{*}(t) d t$ is the cross correlation function between signatures.

The matched filter output contains the self-interference ISI and the MUI. The self-interference ISI is written by this equation:

$$
y_{n / p}^{\text {ISI }}(j)=G\left(\theta_{p / p}\right) \sum_{i} b_{p}^{i} \sum_{l=1}^{L} \beta_{p, l} \rho_{p, p}\left((i-j) T+\tau_{p, n}-\tau_{p, l}\right)
$$

The MUI is:

$$
y_{n / p}^{\text {MUI }}(j)=\sum_{k=1, k \neq p}^{K} \sum_{i} b_{k}^{i} G\left(\theta_{k / p}\right) \sum_{l=1}^{L} \beta_{k, l} \rho_{k, p}\left((i-j) T+\tau_{p, n}-\tau_{k, l}\right)
$$

The noise power after the Beamforming is $\sigma^{2} / \mathrm{M}$. To make the analytic evaluation of error probability computation feasible, we have to assume that the waveforms are randomly generated on each BPSK symbol with outcome uniform on $\{-1,+1\}$.

\subsubsection{MUD Receiver with Adaptive antennas}

The use of adaptive antennas in MUD receivers is expected to be effective mainly in reducing intercell interference. However, to evaluate the advantage of the array processing in reduction of intercell interference, a simplified model can be viewed as a synchronous model with an increased number of fictitious users. Therefore, the synchronous model for one path, $\tau_{1,1}=$ $\tau_{2,1}=\cdots \tau_{\mathrm{K}, 1}=0$ for $\forall \mathrm{k}$, is considered here as a useful example to gain insights on the array processing gain in MUD [9].The received signal after spatial filtering and despreading is:

$$
y_{k, p}[j]=\sum_{k=1}^{K} \sum_{j} b_{k}^{j} \beta_{k, 1} G\left(\theta_{k / p}\right) \rho_{k, p}+\sigma \eta_{p}^{\prime}[j]
$$

for $\mathrm{p}=1,2, \ldots, \mathrm{K}$ 


\subsubsection{Array Gain Approximation}

In our thesis, we assume that the approximation of the array gain $G\left(\theta_{\mathrm{k} / 1}\right)$ is for conventional Beamforming ( $\mathrm{l}=1$ is the user of interest $) \mathrm{w}_{1}=\frac{\mathrm{a}\left(\theta_{1}\right)}{\mathrm{M}}$.

The angular gain function for conventional Beamforming is:

$$
\mathrm{G}\left(\theta \mid \theta_{1}\right)=\mathrm{a}\left(\theta_{1}\right)^{\mathrm{H}} \mathrm{a}(\theta) / \mathrm{M}
$$

$\left|\mathrm{G}_{\mathrm{eq}}\left(\theta \mid \theta_{1}\right)\right|^{2}$ that models the passband (or in-beam) with support $\mathrm{f}_{\mathrm{AoA}}\left(\theta_{1}\right)=\left[\theta_{1}-\right.$ $\left.\theta_{\mathrm{BW}}\left(\theta_{1}\right), \theta_{1}+\theta_{\mathrm{BW}}\left(\theta_{1}\right)\right]$ with a linear gain and the out-beam (with support $\overline{\mathrm{f}}_{\mathrm{AoA}}\left(\theta_{1}\right)$ with an equivalent attenuation $\alpha_{0}$ ). The gain can be approximated by [9]:

$$
\left|G_{\text {eq }}\left(\theta \mid \theta_{1}\right)\right|^{2}= \begin{cases}1-\frac{1}{2} \frac{\left|\theta-\theta_{1}\right|}{\theta_{\mathrm{BW}}\left(\theta_{1}\right)} & \text { for } \theta \in \mathrm{f}_{\mathrm{AoA}}\left(\theta_{1}\right) \\ \alpha_{0} & \text { for } \theta \in \overline{\mathrm{f}}_{\mathrm{AoA}}\left(\theta_{1}\right)\end{cases}
$$

The beamwidth $\theta_{\mathrm{BW}}\left(\theta_{1}\right)$ depends on the number of antennas $\mathrm{M}$ and $\theta_{1}$. The support $\theta=\mathrm{f}_{\text {AoA }}\left(\theta_{1}\right) \cup \overline{\mathrm{f}}_{\mathrm{AoA}}\left(\theta_{1}\right)$ covers all the admissible AoAs $\left(120^{\circ}\right.$ angular sector $)$.

For small deviations from the broadside (for $\theta_{1} \approx 0^{\circ}$ ), the beamwidth $\theta_{\mathrm{BW}}$ can be transformed into the beamwidth for any value $\theta_{1}$ by:

$$
\theta_{\mathrm{BW}}\left(\theta_{1}\right)=\frac{\theta_{\mathrm{BW}}}{\cos \theta_{1}}
$$

In the Beamforming operation, the signals received by the antenna elements are weighted and then summed up.

\subsection{The OQPSK Receiver Model:}

The receiver is divided in four main blocks which can be identified as follows: (1) the array antenna block, (2) the PN despreading, (3) the Beamforming and (4) Walsh correlation and demodulation. We will explain the function of each block:

The first step of the receiver is to obtain the quadrature components at each antenna. We multiply the received waveforms by $\cos \left(\omega_{c} t\right)$ and $\sin \left(\omega_{c} t\right)$ respectively and then Low Pass Filtering (LPF) to remove the double frequency components that results from multiplication [10]. The output of the I-channel and Q-channel low pass filter is given by:

$$
\begin{aligned}
& r_{k, l, n}^{(I)}(t)=\left[r_{k, l, n}(t) \cos \left(\omega_{c} t\right)\right]_{L P F} \\
& =\left\{\beta_{\mathrm{k}, \mathrm{l}} \mathrm{W}_{\mathrm{k}}^{(\mathrm{q})}\left(\mathrm{t}-\tau_{\mathrm{k}, \mathrm{l}}\right) \mathrm{a}_{\mathrm{k}}^{(\mathrm{I})}\left(\mathrm{t}-\tau_{\mathrm{k}, \mathrm{l}}\right) \frac{\cos \varphi_{\mathrm{k}, \mathrm{l}, \mathrm{n}}}{2}\right. \\
& \left.+\beta_{\mathrm{k}, \mathrm{l}} \mathrm{W}_{\mathrm{k}}^{(\mathrm{q})}\left(\mathrm{t}-\mathrm{T}_{0}-\tau_{\mathrm{k}, \mathrm{l}}\right) \mathrm{a}_{\mathrm{k}}^{(\mathrm{Q})}\left(\mathrm{t}-\mathrm{T}_{0}-\tau_{\mathrm{k}, \mathrm{l}}\right) \frac{\sin \varphi_{\mathrm{k}, \mathrm{l}, \mathrm{n}}}{2}\right\} \\
& +\eta^{(\mathrm{I})}(\mathrm{t}) \\
& r_{k, l, n}^{(Q)}(t)=\left[r_{k, l, n}(t) \sin \left(\omega_{c} t\right)\right]_{L P F} \\
& =\left\{\beta_{\mathrm{k}, \mathrm{l}} \mathrm{W}_{\mathrm{k}}^{(\mathrm{q})}\left(\mathrm{t}-\tau_{\mathrm{k}, \mathrm{l}}\right) \mathrm{a}_{\mathrm{k}}^{(\mathrm{Q})}\left(\mathrm{t}-\mathrm{T}_{0}-\tau_{\mathrm{k}, \mathrm{l}}\right) \frac{\cos \varphi_{\mathrm{k}, \mathrm{l}, \mathrm{n}}}{2}\right. \\
& \left.-\beta_{\mathrm{k}, \mathrm{l}} \mathrm{W}_{\mathrm{k}}^{(\mathrm{q})}\left(\mathrm{t}-\mathrm{T}_{0}-\tau_{\mathrm{k}, \mathrm{l}}\right) \mathrm{a}_{\mathrm{k}}^{(\mathrm{I})}\left(\mathrm{t}-\tau_{\mathrm{k}, \mathrm{l}}\right) \frac{\sin \varphi_{\mathrm{k}, \mathrm{l}, \mathrm{n}}}{2}\right\} \\
& +\eta^{(\mathrm{Q})}(\mathrm{t})
\end{aligned}
$$


International Journal of Computer Networks \& Communications (IJCNC) Vol.2, No.6, November 2010

The complex low pass of the received signal can be written as:

$$
\tilde{r}_{k, l, n}(t)=r_{k, l, n}^{(I)}(t)+j r_{k, l, n}^{(Q)}(t)
$$

After filtering, each path is detected by one of the fingers immediately following the radiofrequency stages.

The complex low pass equivalent of the post PN-despread signal is given as $\tilde{y}_{k, l, n}(t)$ :

$$
\tilde{y}_{k, l, n}(t)=y_{k, l, n}^{(I)}(t)+j y_{k, l, n}^{(Q)}(t)
$$

The despreading sequences are denoted as [11]: $\tilde{a}(\mathrm{t})=\mathrm{a}_{\mathrm{k}}^{(\mathrm{I})}\left(\mathrm{t}-\tau_{\mathrm{k}, \mathrm{l}}\right)+\mathrm{ja}_{\mathrm{k}}^{(\mathrm{Q})}\left(\mathrm{t}-\mathrm{T}_{0}-\tau_{\mathrm{k}, \mathrm{l}}\right)$ We can also write as follows:

$$
\begin{aligned}
& \mathrm{y}_{\mathrm{k}, \mathrm{l}, \mathrm{n}}^{(\mathrm{I})}(\mathrm{t})=\mathcal{R}\left\{\left(\tilde{\mathrm{a}}(\mathrm{t}), \tilde{\mathrm{r}}_{\mathrm{k}, \mathrm{l}, \mathrm{n}}(\mathrm{t})\right)\right\}=\mathrm{r}_{\mathrm{k}, \mathrm{l}, \mathrm{n}}^{(\mathrm{I})}(\mathrm{t}) \mathrm{a}_{\mathrm{k}}^{(\mathrm{I})}\left(\mathrm{t}-\tau_{\mathrm{k}, \mathrm{l}}\right)+\mathrm{r}_{\mathrm{k}, \mathrm{l}, \mathrm{n}}^{(\mathrm{Q})}(\mathrm{t}) \mathrm{a}_{\mathrm{k}}^{(\mathrm{Q})}\left(\mathrm{t}-\mathrm{T}_{0}-\tau_{\mathrm{k}, \mathrm{l}}\right) \\
& \mathrm{y}_{\mathrm{k}, \mathrm{l}, \mathrm{n}}^{(\mathrm{Q})}(\mathrm{t})=\mathcal{J}\left\{\left(\tilde{\mathrm{a}}(\mathrm{t}), \tilde{\mathrm{r}}_{\mathrm{k}, \mathrm{l}, \mathrm{n}}(\mathrm{t})\right)\right\}=\mathrm{r}_{\mathrm{k}, \mathrm{l}, \mathrm{n}}^{(\mathrm{I})}(\mathrm{t}) \mathrm{a}_{\mathrm{k}}^{(\mathrm{Q})}\left(\mathrm{t}-\mathrm{T}_{0}-\tau_{\mathrm{k}, \mathrm{l}}\right)-\mathrm{r}_{\mathrm{k}, \mathrm{l}, \mathrm{n}}^{(\mathrm{Q})}(\mathrm{t}) \mathrm{a}_{\mathrm{k}}^{(\mathrm{I})}\left(\mathrm{t}-\tau_{\mathrm{k}, \mathrm{l}}\right)
\end{aligned}
$$

Where $(a, b)=a \cdot b^{*}$ the product between complex numbers.

$\tilde{y}_{k, l, n}$ can be written in vector notation as:

$$
\mathrm{Y}_{\mathrm{k}, \mathrm{l}}=\left[\mathrm{y}_{\mathrm{k}, \mathrm{l}, 1}, \mathrm{y}_{\mathrm{k}, \mathrm{l}, 2}, \ldots, \mathrm{y}_{\mathrm{k}, \mathrm{l}, \mathrm{M}}\right]^{\mathrm{T}}
$$

In the next step, the signal after PN despreading is combined by the beamformer. In the Beamforming operation, the signals received by antenna elements are weighted by complex weights and then summed up.

The smart antenna output is given by:

$$
\begin{gathered}
\mathrm{Z}_{\mathrm{k}, \mathrm{l}}=\left(\mathrm{W}_{\mathrm{k}, \mathrm{l}}\right)^{\mathrm{H}} \mathrm{Y}_{\mathrm{k}, \mathrm{l}} \\
\tilde{\mathrm{Z}}_{\mathrm{k}, \mathrm{l}}(\mathrm{t})=\mathrm{Z}_{\mathrm{k}, \mathrm{l}}^{(\mathrm{I})}(\mathrm{t})+j \mathrm{Z}_{\mathrm{k}, \mathrm{l}}^{(\mathrm{Q})}(\mathrm{t})
\end{gathered}
$$

Where $W_{k, 1}$ is the Beamforming weight vector given by:

$$
\mathrm{W}_{\mathrm{k}, \mathrm{l}}=\left[\mathrm{W}_{\mathrm{k}, \mathrm{l}, 1}, \mathrm{~W}_{\mathrm{k}, \mathrm{l}, 2}, \ldots, \mathrm{W}_{\mathrm{k}, \mathrm{l}, \mathrm{M}}\right]^{\mathrm{T}}
$$

To simplify our work, we assume that the weights are set as $\mathrm{W}_{\mathrm{k}, \mathrm{l}}=\mathrm{h}_{\mathrm{k}, \mathrm{l}}$ and these vector channel coefficients are assumed to be perfectly known. This provides the best case system performance.

The last step is the correlation of the smart antenna output with stored replicas of the Walsh functions to form the decision variable for demodulation.

The output of the $\mathrm{q}^{\text {th }}$ Walsh correlator $(\mathrm{q}=1,2, \ldots, \mathrm{Q})$ for single antenna is:

$$
\mathrm{Z}_{\mathrm{k}, \mathrm{l}}^{(\mathrm{I})}(\mathrm{q})=\frac{1}{\mathrm{~T}_{\mathrm{W}}} \int_{\tau_{\mathrm{k}, \mathrm{l}}}^{\mathrm{T}_{\mathrm{W}}+\tau_{\mathrm{k}, \mathrm{l}}}\left[\mathrm{Z}_{\mathrm{k}, \mathrm{l}}^{(\mathrm{I})} \mathrm{W}^{(\mathrm{q})}\left(\mathrm{t}-\tau_{\mathrm{k}, \mathrm{l}}\right)+\mathrm{Z}_{\mathrm{k}, \mathrm{l}}^{(\mathrm{I})} \mathrm{W}^{(\mathrm{q})}\left(\mathrm{t}-\mathrm{T}_{0}-\tau_{\mathrm{k}, \mathrm{l}}\right)\right] \mathrm{dt}
$$


International Journal of Computer Networks \& Communications (IJCNC) Vol.2, No.6, November 2010

$\mathrm{Z}_{\mathrm{k}, \mathrm{l}}^{(\mathrm{Q})}(\mathrm{q})=\frac{1}{\mathrm{~T}_{\mathrm{W}}} \int_{\tau_{\mathrm{k}, \mathrm{l}}}^{\mathrm{T}_{\mathrm{W}}+\tau_{\mathrm{k}, \mathrm{l}}}\left[\mathrm{Z}_{\mathrm{k}, \mathrm{l}}^{(\mathrm{Q})} \mathrm{W}^{(\mathrm{q})}\left(\mathrm{t}-\tau_{\mathrm{k}, \mathrm{l}}\right)+\mathrm{Z}_{\mathrm{k}, \mathrm{l}}^{(\mathrm{Q})} \mathrm{W}^{(\mathrm{q})}\left(\mathrm{t}-\mathrm{T}_{0}-\tau_{\mathrm{k}, \mathrm{l}}\right)\right] \mathrm{dt}$

The decision variable for the $\mathrm{l}^{\text {th }}$ multipath of the $\mathrm{k}^{\text {th }}$ user is obtained from the previous values:

$$
\mathrm{u}_{\mathrm{k}, \mathrm{l}}(\mathrm{q})=\left(\mathrm{Z}_{\mathrm{k}, \mathrm{l}}^{(\mathrm{I})}\right)^{2}+\left(\mathrm{z}_{\mathrm{k}, \mathrm{l}}^{(\mathrm{Q})}\right)^{2}
$$

The overall decision variable is obtained by Equal Gain Combining (EGC) of all the decision variables from the L multipaths as [12]:

$$
\mathrm{u}_{\mathrm{k}}(\mathrm{q})=\sum_{\mathrm{l}=1}^{\mathrm{L}} \mathrm{u}_{\mathrm{k}, \mathrm{l}}(\mathrm{q})=\sum_{\mathrm{l}=1}^{\mathrm{L}}\left[\left(\mathrm{Z}_{\mathrm{k}, \mathrm{l}}^{(\mathrm{I})}\right)^{2}+\left(\mathrm{Z}_{\mathrm{k}, \mathrm{l}}^{(\mathrm{Q})}\right)^{2}\right]
$$

Finally, the receiver makes a hard decision on the $\mathrm{q}^{\text {th }}$ symbol of the $\mathrm{k}^{\text {th }}$ user by using the Maximum Likelihood Criteria rule as:

$$
\hat{\mathrm{q}}=\arg _{\mathrm{q}=1, \ldots, \mathrm{Q}} \max \left\{\mathrm{u}_{\mathrm{k}}(\mathrm{q})\right\}
$$

\section{Error Probability Analysis}

\subsection{Error Probability for BPSK receiver model:}

In CDMA system with adaptive antenna array of antennas, the effect of spatial filter is to enhance the differences in the power of interfering users.

The average error probability of a generic adaptive antenna receiver is given by [9]

$$
\mathrm{P}_{\mathrm{e}}^{(2-\mathrm{D})}(\mathrm{E})=\sum_{\mathrm{K}_{\mathrm{I}}=0}^{\mathrm{K}-1} \eta^{\mathrm{K}_{\mathrm{I}}} \chi\left(\eta, \mathrm{K}, \mathrm{K}_{\mathrm{I}}\right)\left(\begin{array}{c}
\mathrm{K}-1 \\
\mathrm{~K}_{\mathrm{I}}
\end{array}\right) \mathrm{P}_{\mathrm{e}}^{(1-\mathrm{D})}(\mathrm{E})
$$

Where $K_{I}$ denotes the number of in-beam interferers, $\left(K-K_{I}-1\right)$ is the number of out-beam interferers, $\mathrm{P}_{\mathrm{b}}^{(1-\mathrm{D})}$ is the probability of bit error for the scalar (single) antenna receiver, depends on the Beamforming criterion exploited and $\chi$ are defined as [9]

$$
\begin{gathered}
\eta=\frac{2 \theta_{\mathrm{BW}}}{\Delta \theta} \\
\chi=(1-\eta)^{\mathrm{K}-\mathrm{K}_{\mathrm{I}}-1}
\end{gathered}
$$

We will consider in this section, the two cases of receiver with no-fading channel and in Rayleigh fading channels

\subsubsection{Error Probability in No-fading Channels}

The average error probability for asynchronous CDMA systems has been widely investigated. A simple but accurate approximation was derived under the Gaussian approximation (for random spreading sequence of length $\mathrm{N}$ ) with $\mathrm{M}=1$ is given by [9]:

$$
\mathrm{P}_{\mathrm{e}}^{(1-\mathrm{D})}(\mathrm{E})=\mathrm{Q}\left[\left(\frac{\sigma^{2}}{\mathrm{~A}^{2}}+\frac{\mathrm{K}_{\mathrm{I}}}{3 \mathrm{~N}}\right)^{-1 / 2}\right]=\frac{1}{2}\left(1-\frac{1}{\sqrt{1+\frac{\sigma^{2}}{\mathrm{~A}^{2}}+\frac{\mathrm{K}_{\mathrm{I}}}{3 \mathrm{~N}}}}\right)
$$

$\mathrm{Q}[$. ]is the Gaussian Q-function. 
The error probability for an adaptive array of $M$ antennas can be obtained by substituting (35) in (32) gives an approximation for the error probability for an adaptive antenna array receiver.

$$
\mathrm{P}_{\mathrm{e}}^{(2-\mathrm{D})}(\mathrm{E})=\sum_{\mathrm{K}_{\mathrm{I}}=0}^{\mathrm{K}-1} \eta^{\mathrm{K}_{\mathrm{I}}} \chi\left(\eta, \mathrm{K}, \mathrm{K}_{\mathrm{I}}\right)\left(\begin{array}{c}
\mathrm{K}-1 \\
\mathrm{~K}_{\mathrm{I}}
\end{array}\right) \mathrm{Q}\left[\left(\frac{\sigma^{2}}{\mathrm{MA}^{2}}+\gamma\left(\mathrm{K}_{\mathrm{I}}\right)\right)^{-1 / 2}\right]
$$

Where:

$$
\gamma\left(\mathrm{K}_{\mathrm{I}}\right)=\frac{\mathrm{K}_{\mathrm{I}}}{4 \mathrm{~N}}+\alpha_{0} \frac{\mathrm{K}-\mathrm{K}_{\mathrm{I}}-1}{3 \mathrm{~N}}
$$

Denotes the equivalent noise increasing due to the multi-access interference.

\subsubsection{Error probability in Rayleigh fading Channels}

In this section, we extend the concepts discussed above to the Rayleigh fading case.

The error probability of BPSK for propagation over Rayleigh faded channel $(K=1$ and $M=1)$ is given by [11]:

$$
\mathrm{P}_{\mathrm{e}}^{(1-\mathrm{D})}(\mathrm{E})=\frac{1}{2}\left(1-\frac{1}{\sqrt{1+\frac{\sigma^{2}}{\sigma_{\mathrm{A}}^{2}}}}\right)
$$

The overall impairment is the superposition of the AWGN and $\mathrm{K}_{\mathrm{I}}$ interferers.

The error probability for asynchronous CDMA with $\mathrm{K}_{\mathrm{I}}$ interferers is equivalent to the error probability for two fictitious interferers per actual interferer [13], thus doubling the overall number of interferers. The power of the interference (for random spreading sequence of length $\mathrm{N}) i \sigma_{\mathrm{I}}^{2}=2 \sigma_{\mathrm{A}}^{2} \mathrm{~K}_{\mathrm{I}} / 3 \mathrm{~N}$. The error probability of the asynchronous CDMA system for Rayleigh fading channel and with one antenna becomes:

$$
\mathrm{P}_{\mathrm{e}}^{(1-\mathrm{D})}(\mathrm{E})=\frac{1}{2}\left(1-\frac{1}{\sqrt{1+\frac{\sigma^{2}}{\sigma_{\mathrm{A}}^{2}}+\frac{2 \mathrm{~K}_{\mathrm{I}}}{3 \mathrm{~N}}}}\right)
$$

The error probability for an adaptive array of $\mathrm{M}$ antennas can be obtained by substituting (39) to (32) and increasing the overall noise to signal ratio accordingly:

$$
P_{e}^{(2-D)}(E)=\sum_{K_{I}=0}^{K-1} \eta^{K_{I}} \chi\left(\eta, K, K_{I}\right)\left(\begin{array}{c}
K-1 \\
K_{I}
\end{array}\right) Q\left[\left(\frac{\sigma^{2}}{M \sigma_{A}^{2}}+\gamma\left(K_{I}\right)\right)^{-1 / 2}\right]
$$

where

$$
\gamma\left(\mathrm{K}_{\mathrm{I}}\right)=\frac{\mathrm{K}_{\mathrm{I}}}{2 \mathrm{~N}}+2 \alpha_{0} \frac{\mathrm{K}-\mathrm{K}_{\mathrm{I}}-1}{3 \mathrm{~N}}
$$

\subsection{Error Probability for OQPSK receiver model:}

4.2.1. Error probability for Rayleigh fading channel

For Rayleigh fading channels, the mean BER for a conventional receiver with single antenna (without Beamforming) with L-fold multipath diversity and Equal Gain Combining (EGC) is given by [10]: 
International Journal of Computer Networks \& Communications (IJCNC) Vol.2, No.6, November 2010

$$
=\frac{M / 2}{M-1} \sum_{m=1}^{M-1}\left(\begin{array}{c}
M-1 \\
m
\end{array}\right) \frac{(-1)^{m+1}}{(1+m+m \rho)^{L}} \sum_{l=0}^{P_{e}^{(1-D)}(E)} C_{l}(m)\left(\begin{array}{c}
L+l-1 \\
l
\end{array}\right)\left(\frac{1+\rho}{1+m+m \rho}\right)^{l}
$$

Where $\mathrm{C}_{l}(\mathrm{~m})$ is given by [10]:

$\mathrm{C}_{0}(\mathrm{~m})=1$ for all $\mathrm{m}$.

$$
C_{l}(m)=\left\{\begin{array}{l}
\frac{1}{l} \sum_{q=1}^{l}\left(\begin{array}{l}
l \\
q
\end{array}\right)[(m+1) q-l] C_{l-q}(m) ; l \leq L-1 \\
\frac{1}{1} \sum_{q=1}^{L-1}\left(\begin{array}{l}
l \\
q
\end{array}\right)[(m+1) q-l] C_{l-q}(m) \quad ; l>L
\end{array}\right.
$$

For the case of no multipath diversity $(\mathrm{L}=1) ;(42)$ reduces to:

$\rho=\frac{\gamma}{1+\frac{2}{3 \mathrm{~N}_{\mathrm{c}}} \gamma(\mathrm{K}-1)}$

$$
\mathrm{P}_{\mathrm{e}}^{(1-\mathrm{D})}(\mathrm{E})=\frac{\mathrm{M} / 2}{\mathrm{M}-1} \sum_{\mathrm{m}=1}^{\mathrm{M}-1}\left(\begin{array}{c}
\mathrm{M}-1 \\
\mathrm{~m}
\end{array}\right) \frac{(-1)^{\mathrm{m}+1}}{1+\mathrm{m}+\mathrm{m} \rho}
$$

\subsubsection{Error probability for Ricean fading channel}

For Ricean Fading Channels, the mean BER for a conventional receiver with single antenna (without Beamforming) is given by [14]:

$$
\mathrm{P}_{\mathrm{e}}^{(1-\mathrm{D})}(\mathrm{E})=\frac{\mathrm{M} / 2}{\mathrm{M}-1} \sum_{\mathrm{m}=1}^{\mathrm{M}-1}\left(\begin{array}{c}
\mathrm{M}-1 \\
\mathrm{~m}
\end{array}\right) \frac{(-1)^{\mathrm{m}+1}}{1+\mathrm{m}+\mathrm{m} \delta_{2}} \exp \left(\frac{-\mathrm{m} \delta_{1}}{1+\mathrm{m}+\mathrm{m} \delta_{2}}\right)
$$

where the variables $\delta_{1}$ et $\delta_{2}$ are given by:

$$
\begin{aligned}
& \delta_{1}=\frac{\rho}{1+\frac{1}{K_{R}}} \\
& \delta_{2}=\frac{\rho}{1+K_{R}}
\end{aligned}
$$

$\mathrm{K}_{\mathrm{R}}$ is the Rice factor.

\section{Computation Results AND Discussion:}

\subsection{Simulation results for BPSK receiver:}

Figure 3 illustrates the average BER versus the number of users $\mathrm{K}$ for no-fading and Rayleigh fading channels ( $L=1$ path), for $M=8,16$ antennas. It can be noticed that the same average BER can be obtained by doubling the number of antennas $\mathrm{M}$ and the number of users $\mathrm{K}$ either for no-fading or fading channels.

Figure 4 shows the average BER versus the number of users $\mathrm{K}$ for propagation over $\mathrm{L}$ paths frequency selective Rayleigh fading channel (for $\mathrm{L}=1,2,4$ ). The figures demonstrate either for varying SNR (previous section) or increasing number of users that multipath channels (large L) and angular diversity can significantly improve the performance when exploited jointly. 
International Journal of Computer Networks \& Communications (IJCNC) Vol.2, No.6, November 2010

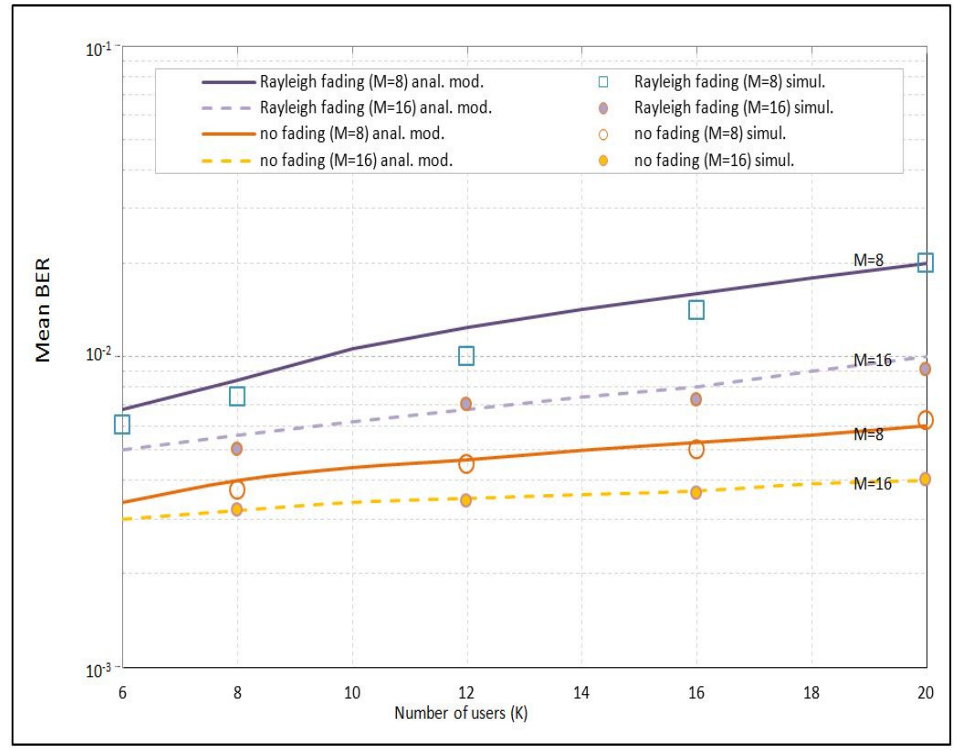

Figure 3: Average BER versus the number of users $\mathrm{K}$ for no-fading and Rayleigh fading channels for $\mathrm{L}=1$ path, $\mathrm{M}=8,16$ antennas

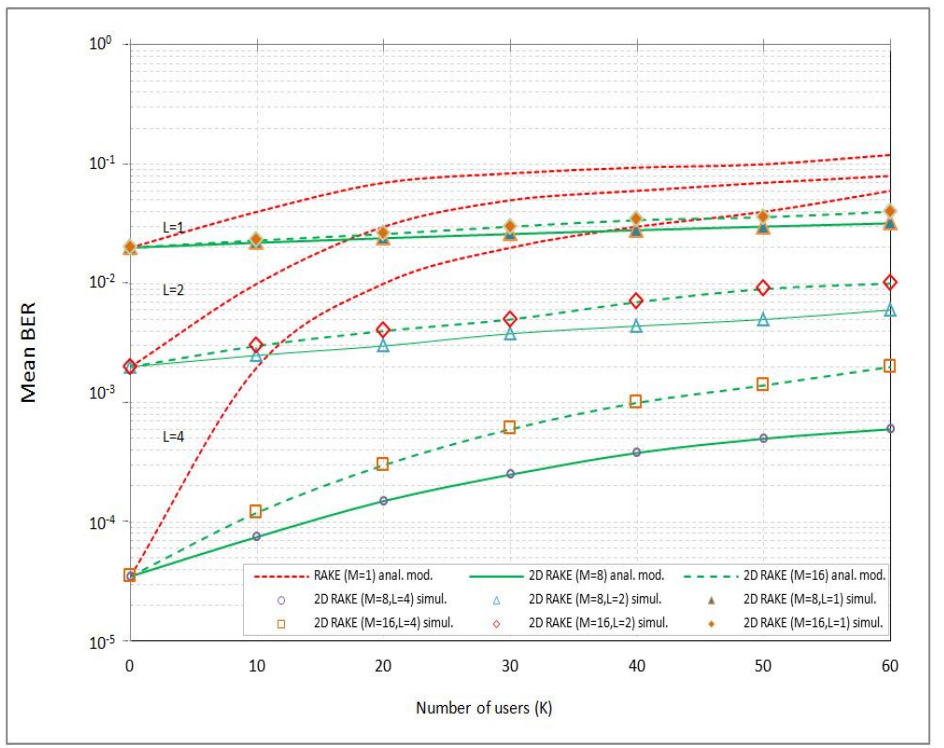

Figure 5: Average BER versus the number of users $\mathrm{K}$ in multipath $\mathrm{L}=1,2,4$ for Rayleigh fading channels with $\mathrm{M}=8$ and 16 antennas

Figure 3 and figure 4, illustrate both the effect of varying the number of users and the number of antennas by doubling the number of antennas in each case $(M=8$ and 16). Also, it can be noticed that the same average BER can be obtained by doubling the number of antennas $M$ and the number of users $\mathrm{K}$ either for no-fading or Rayleigh fading channels (for $\mathrm{L}=1$ ). Therefore, as a rule of thumb, the average performance (or the level of the in-beam interference) remains the same as far as the ratio $\mathrm{M} / \mathrm{K}$ remains constant. 
International Journal of Computer Networks \& Communications (IJCNC) Vol.2, No.6, November 2010

\subsection{Simulation results for OQPSK receiver}

5.2.1. Ricean fading channels:

Figure 5 shows the average $B E R$ versus $E_{b} / N_{0}$ for $M=8$ antennas, $K=1$ user with single path assuming Ricean fading with Rice factor $K_{R}=1,5,7,10 \mathrm{~dB}$ respectively.

We also show as reference the performance in Rayleigh fading (corresponding to $\mathrm{K}_{\mathrm{R}}=-\infty \mathrm{dB}$ ) and conventional receiver ( $\mathrm{M}=1$ with no Beamforming).

From Figure 5, it can be noticed that Beamforming improves the performance of the system. We realize that for low values of Rice factor, the performance is very close to the performance in Rayleigh fading. However for larger Rice factors, there is a tremendous improvement in the average BER. The simulation results show good agreements with analytical results for different Ricean factors.

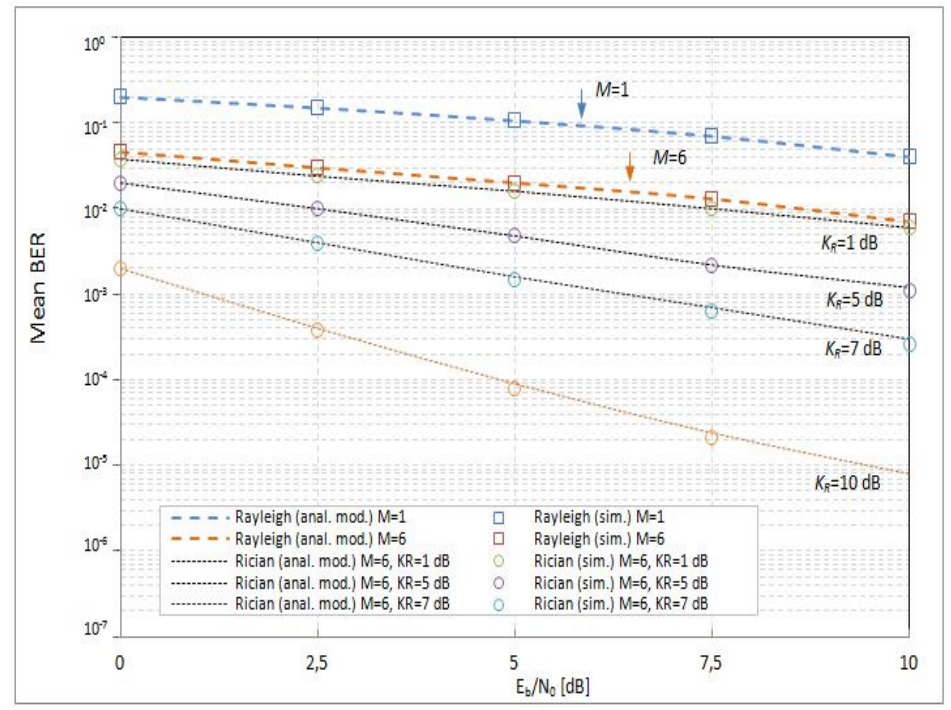

Figure 5: Average BER versus $\mathrm{E}_{\mathrm{b}} / \mathrm{N}_{0}$ for $\mathrm{M}=6$ antennas, $\mathrm{K}=1$ with $\mathrm{L}=1$ path for Ricean and Rayleigh fading channels (for Ricean fading $\mathrm{KR}=1,5,7,10 \mathrm{~dB}$ )

Figure 6 illustrates the average BER versus number of users $K$ for $\frac{E_{b}}{N_{0}}=10 \mathrm{~dB}, M=6, L=1$ path/user in Ricean fading channel with different Rice factors. It is also shown as reference curves for single antenna and Rayleigh fading channels.

The figure shows that as the number of users increases, the performance of the system gradually deteriorates.

However, as for the case of a single user, there is an improvement in performance with the increase in $K_{R}$. Also, we can realize that for a specific number of users $K=15$, we notice that for $\mathrm{KR}=5 \mathrm{~dB}$ over Ricean fading channel, the BER improves by approximately a factor of 4 versus the Rayleigh fading channel case. The figure shows that the analytical model provides a good much with simulation results for multi-user scenarios as well. 
International Journal of Computer Networks \& Communications (IJCNC) Vol.2, No.6, November 2010

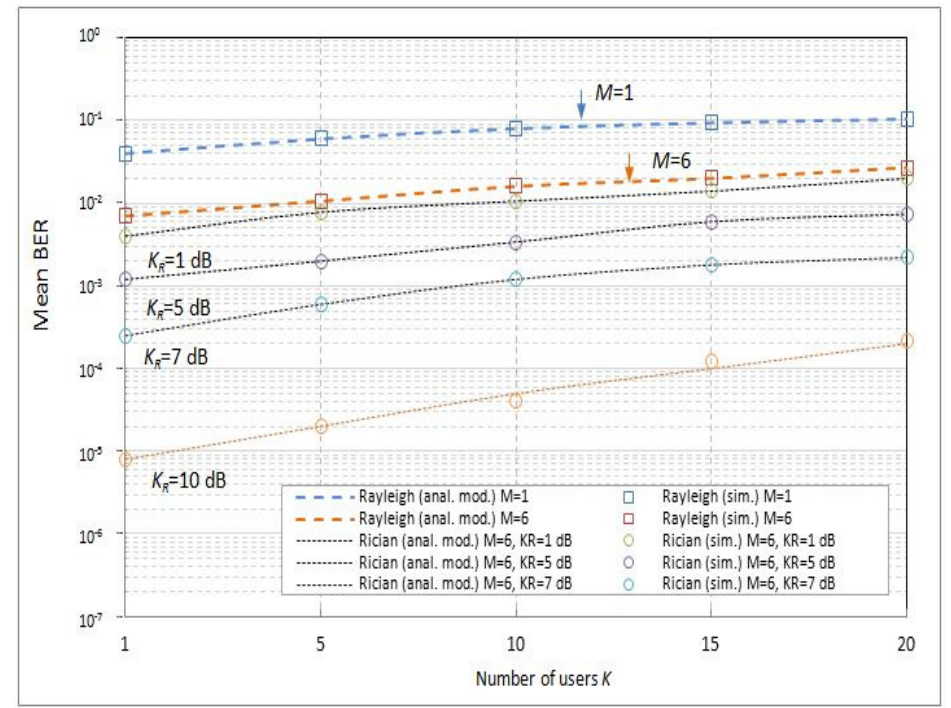

Figure 6: Average BER versus number of users $K$ for $E_{b} / N_{0}=10 d B, M=6$ antennas, $L=1$ path/user in Rayleigh and Ricean channels

\subsubsection{Rayleigh fading channels:}

Figure 7 illustrates the average BER versus number of users, for $E_{b} / N_{0}=10 \mathrm{~dB}$ for $M=1,4,6$ and 8 in Rayleigh channels $(\mathrm{L}=1,2)$. We always compare with the reference curves for single antenna $(M=1)$, it is clear that Beamforming improves the performance of the system considerably. We can realize from the figure that as the number of users increases, the analytical model provides a closer match with simulation results.

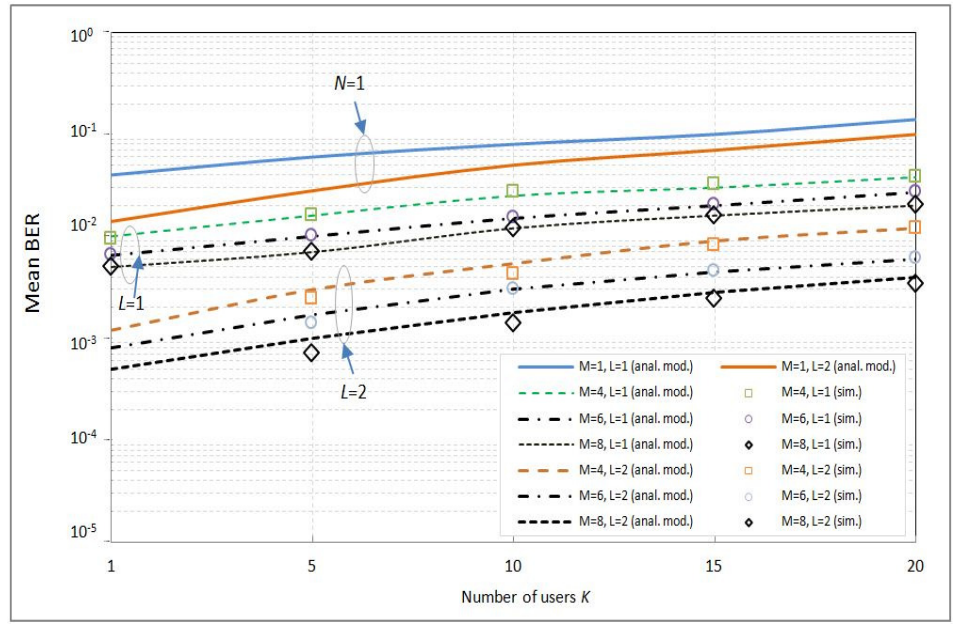

Figure 5: Average BER versus the number of users $K$ for $E_{b} / N_{0}=10 d B, M=1,4,6,8$ in Rayleigh fading channels $(\mathrm{L}=1,2)$ 


\section{Conclusions:}

This paper focused on the performance of smart antenna receiver with two types of modulation in the transmitted model (BPSK modulation and non-coherent M-ary orthogonal modulation) in Rayleigh and Ricean fading environments.

A simple analytical model has been proposed which evaluates merely the BER performance using a closed-form expression. The results obtained using this analytical model show good agreements with the simulation results.

An important parameter of the Adaptive antenna receiver with regards to quality and capacity of reducing interference is the number of users. That's why; we focused our work in varying the number of users and also to compare the BER performance.

In the two cases, we assessed the impact of smart antenna systems, we considered the case of conventional single antenna receiver model as reference (single user/ single antenna lower band for AWGN).

Also, we showed in simulations that we can influence in the number of antennas to evaluate BER. The BER is expected to fall well below the optimum when more number of antennas is used, but with a trade-off of increased cost and complexity. Besides, we noticed that the average performance (or the level of the in-beam interference) remains the same as far as the ratio $M / K$ remains constant.

A continuation of the study, which we have already started, is to evaluate the average BER in forward link (base to mobiles) where each user experience the same temporal channel for all the received signals. In this case, the beamforming at the base station is decoupled from the receiver at the mobile terminals. In addition, the beamforming design could be synergic with the MUD receiver at mobiles.

\section{REFERENCES}

[1] D. Piazza, N.J. Kirsh, A. Forenza, "Design and Evaluation of a reconfigurable antenna array for MIMO systems”, IEEE Transactions on Antennas and Propagation, vol.56, n³, pp. 869-881, March 2008.

[2] R. Haddad, R. Bouallègue, "BER Performance in DS-CDMA Systems using a Beamformer", IEEE International Symposium on Industrial Electronics, vol.1, pp. 585-588, July 2006.

[3] Li Zhang, NingXie, "Non linear optimization for adaptive antenna array receivers with a small datarecord size", Wireless Communications \& Mobile Computing, vol.9, pp. 239-249, Feb. 2009.

[4] H. J. Li and T. Y. Liu, "Comparison of beamforming techniques for W-CDMA communication systems”, IEEE Transactions on Vehicular Technology, vol.52, no.4, pp. 752-760, July 2003.

[5] B. A. Bjerke, Z. Zvonar, and J. G. Proakis, "Antenna diversity combining aspects for WCDMA systems in fading multipath channels", IEEE Transactions on Wireless Communications, vol. 3, no. 1, pp. 97-106, Jan. 2004.

[6] MonzigoA.Roberts, Miller Thomas, Introduction to Adaptive Arrays. Sc Tech Publishing, 2004.

[7] Y. H. Lee and al, "Performance Analysis of conventional coded DS/CDMA System in Nakagami Fading Channels” Telecommunication Systems journal Springer, 2000.

[8] L. M. Jalloul and J. M. Holtzman, "Performance analysis of DS/CDMA with non-coherent M-ary orthogonal modulation in multipath fading channels," IEEE Journal on Selected Areas in Communications, vol. 12, no. 5, pp. 862-870, June 1994. 
International Journal of Computer Networks \& Communications (IJCNC) Vol.2, No.6, November 2010

[9] U. Spagnolini, "A simplified model for probability of error in DS/CDMA systems with adaptive antenna arrays," in Proc. IEEE International Conference on Communications (ICC), June 2001, pp. $2271-2275$

[10] T. S. Rappaport, Wireless Communications: Principles and Practice, 2nd ed. Prentice Hall, 2002.

[11] G. L. Stuber, Principles of Mobile Communication, 2nd ed. Kluwer Academic Publishers, 2001.

[12]C. D. Iskander and P. T. Mathiopoulos, "Performance of multicode DS/CDMA with M-ary orthogonal modulation in multipath fading channels," IEEE Transactions on Wireless Communications, vol. 3, no.1, pp. 209-223, Jan. 2004.

[13] S. Verdu, Multiuser Detection, Cambridge University Ed, 1998

[14]P. J. Crepeau, "Uncoded and coded performance of MFSK and DPSK in Nakagami fading channels," IEEE Transactions on Communications, vol. 40, no. 3, pp. 487-493, Mar. 1992.

\section{Authors}

Rim Haddad (M'05) Received the B. Eng. Degrees in Telecommunication from the High School of Telecommunication of Tunis (SUP'COM). From 1997 to December 2006, she was Engineer in Telecommunication in Tunisie Telecom. Since January 2007 she was an university assistant in the High School of Computing, she has taught courses in telecommunications and security computing. She is currently working toward the Ph.D. degree in Telecommunication systems also at the High School of Telecommunication of Tunis in the Laboratory research of System Telecommunication (6'Tel).

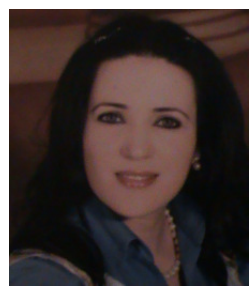

She has worked in several areas including smart antennas, space-time receivers, and angular gain.She's current research interests include smart antenna systems, compact antenna design, and propagation characterization for wireless communications.Ms. Rim won the best paper award of the IEEE-ISIE conference in Montreal Canada.

RidhaBouallègue (M'98) received the Ph.D degrees in electronic engineering from the National Engineering School of Tunis. In Mars 2003, he received the Hd.R degrees in multiuser detection in wireless communications. From September 1990 he was a graduate Professor in the higher school of communications of Tunis (SUP'COM), he has taught courses in communications and electronics. From 2005 to 2008, he was the Director of the National engineering school of Sousse. In 2006, he was a member of the national committee of science technology. Since 2005, he was the laboratory research in telecommunication Director'sat SUP'COM

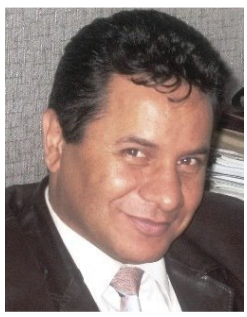

From 2005 he served as a member of the scientific committee of validation of thesis and Hd.R in the higher engineering school of Tunis. His current research interests include wireless and mobile communications, OFDM, space-time processing for wireless systems, multiuser detection, wireless multimedia communications, and CDMA systems. 